\title{
Thermal, glass-forming, nonlinear optical and holographic properties of "push-pull" type azochromophores with triphenyl moieties containing isophorene and pyranylidene fragments
}

\author{
Elmars Zarins ${ }^{\mathrm{a} *}$, Andrejs Tokmakovs ${ }^{\mathrm{b}}$, Zane Kalnina ${ }^{\mathrm{b}}$, Valdis Kokars ${ }^{\mathrm{a}}$, Martins Rutkis ${ }^{\mathrm{b}}$, Andris

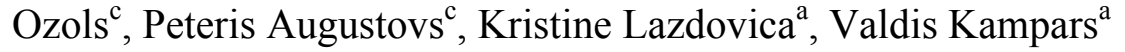 \\ ${ }^{a}$ Riga Technical University, Institute of Applied Chemistry, 14/24 Azenes Str., Riga LV-1048, \\ Latvia; \\ ${ }^{\mathrm{b}}$ Institute of Solid State Physics, University of Latvia, 8 Kengaraga Str., Riga LV-1063, Latvia; \\ ${ }^{c}$ Riga Technical University, Institute of Technical Physics, 14/24 Azenes Str., Riga LV-1048, \\ Latvia
}

\begin{abstract}
Molecular organic compounds with electron donating fragment bounded through $\pi$-conjugated system with electron acceptor fragment, as well as with incorporated triphenyl groups in their molecules show potential for creating cheap and simple solution processable materials with nonlinear optical properties. Additional insertion of azobenzene fragment in their structures makes them also possible to form holographic volume and surface relief gratings (SRG) after exposure to laser radiation, which could be useful for holographic data storage. For these purposes polymers are generally used. However, their application is complicated and challenging task as in every attempt to obtain the same polymer it will have different physical properties. On the other hand, the synthetic procedure of molecular glasses is more simple as their structure and physical properties are strongly defined. Unfortunately, there is still no clear relation between compound organic structures and their thermal, glass-forming and optical properties.

In order to investigate the above mentioned regularities, we have synthesized and investigated ten molecular glassy organic compounds with three different fragments as main backbones of the molecules: indene-1,3-dione (WE-1, WE-2, WE-3), isophorene (IWK-1D, IWK-2M, IWK-2D) and pyranylidene (DWK-2TB, ZWK-2TB, JWK-2TB, ZWK-3AZO). Compounds containing isophorene fragment in their molecules had the highest NLO efficiencies $\left(\mathrm{d}_{33}\right.$ up to $125.7 \mathrm{pm} / \mathrm{V}$ for IWK-2D) and also were the most effective holographic data storage compounds with holographic self diffraction efficiency $13 \%$ and holographic diffraction efficiency $20 \%$, also for IWK-2D, but their thermal stability $\left(\mathrm{T}_{\mathrm{d}}\right.$ from $288^{\circ} \mathrm{C}$ to $295^{\circ} \mathrm{C}$ ) and glass transition $\left(\mathrm{T}_{\mathrm{g}}\right.$ from $90^{\circ} \mathrm{C}$ to $105^{\circ} \mathrm{C}$ ) values were just average. Pyranylidene type compounds had the highest thermal stability and highest glass transition $\left(\mathrm{T}_{\mathrm{g}}\right.$ from $115^{\circ} \mathrm{C}$ to $\left.180^{\circ} \mathrm{C}\right)$. But their ability to form and maintain amorphous structure were low and they had average NLO efficiencies ( $\mathrm{d}_{33}$ up to $66.2 \mathrm{pm} / \mathrm{V}$ for ZWK-2TB) and average holographic self diffraction efficiency $2 \%$ and holographic diffraction efficiency $8 \%$ for ZWK-3AZO. The molecules with just azobenzene fragment and indene-1,3-dione as electron acceptor has the lowest thermal $\left(\mathrm{T}_{\mathrm{d}}\right.$ from $250^{\circ} \mathrm{C}$ to $282^{\circ} \mathrm{C}, \mathrm{T}_{\mathrm{g}}$ from $70^{\circ} \mathrm{C}$ to $98^{\circ} \mathrm{C}$ ) and also the lowest holographic properties with holographic diffraction and self diffraction efficiencies at $4 \%$ for WE-1 and lower for other compounds. Nevertheless, some of the investigated molecular glasses show potential as multifunctional optical materials.
\end{abstract}

Keywords: Molecular glasses, SRG, NLO, holographic gratings, azobenzene, isophorene, pyranylidene

\section{INTRODUCTION}

In the last decade the organic compounds with electron donating fragment bounded through $\pi$-conjugated system with electron acceptor fragment in their molecules have attracted considerable attention of scientists due to their potential applications as optical materials - such as materials for nonlinear optics (NLO) and materials for holographic data storage. Comparing to inorganic crystals, which were already used for this purpose, the organic materials obtained in synthesis are flexible, light and have low-cost fabrication possibility ${ }^{1}$. Many different small organic molecules with the above mentioned optical properties have been synthesized an investigated ${ }^{1-5}$.

*Elmars.Zarins@rtu.lv

Organic Photonic Materials and Devices XV, edited by Christopher E. Tabor, François Kajzar, Toshikuni Kaino, Yasuhiro Koike, Proc. of SPIE Vol. 8622, 86221H · (c) 2013 SPIE · CCC code: 0277-786X/13/\$18 doi: $10.1117 / 12.2003085$ 
To enable the low-cost optical device fabrication opportunity, the already described small organic molecules been either attached to the main or side chain of the polymers ${ }^{1,6-7}$, or mixed into a polymer matrix creating a "host-guest" system ${ }^{1,8-}$ ${ }^{10}$. However their application is complicated and challenging task as in every attempt to obtain the same polymer it will have different physical properties. The another disadvantage is the inert volume of the material which is composed from the active chromophore part and the larger glass-forming polymer part ${ }^{1}$. Lastly, the phase separation problem might occur in the polymer composites with too high concentration of the chromophores ${ }^{1,9}$.

In our previous researches ${ }^{11-13}$ we have discovered, that incorporating triphenyl groups in the low molecular mass organic molecules enables their excellent solubility in non-polar organic solvents and are able to form good optical quality glassy films without mixing in a polymer matrix. Such materials with nonlinear optical activity ${ }^{11}$, light-emitting ${ }^{12-}$ ${ }^{13}$ and amplified spontaneous emission properties ${ }^{14-15}$ have been synthesized and investigated by us. Additional insertion of azobenzene fragment in their structures makes them also possible to form holographic volume and surface relief gratings (SRG) after exposure to laser radiation. This physical phenomena could be used for information and holographic data storage ${ }^{16-17}$. Unfortunately, there is still no clear relation between compound organic structures and their thermal, glass-forming and optical properties.

In order to investigate the above mentioned regularities, we have synthesized and investigated ten molecular glassy organic compounds with three different fragments as main backbones of the molecules: indene-1,3-dione (WE-1, WE-2, WE-3), isophorene (IWK-1D, IWK-2M, IWK-2D) and pyranylidene (DWK-2TB, ZWK-2TB, JWK-2TB, ZWK3AZO). Our findings on their structural relation with thermal, glass-forming, nonlinear optical and holographic properties will be described in this report.

\section{MATERIALS AND METHODS}

Required solvents (dichloromethane and chloroform) for obtaining thin solid films from their solutions were dried by refluxing with calcium hydride and distilled. The ${ }^{1} \mathrm{H}-\mathrm{NMR}$ spectra on investigated organic compounds were obtained on a Bruker UXNMR/XWIN-NMR spectrometer (300 MHz).

\subsection{Investigated compounds}

We have synthesized ten glassy organic compounds [Fig.1.] which could be grouped in three different classes with similar key molecular fragments:

1) Azobenzene group containing molecular glasses with indene-1,3-dione as electron acceptor fragment - 2-(4-((4(Ethyl(2-(trityloxy)ethyl)amino)phenyl)diazenyl)benzylidene)-1 $H$-indene-1,3(2H)-dione (WE-1), 2-(4-((4(Bis(2-(trityloxy)ethyl)amino)phenyl)diazenyl)benzylidene)-1H-indene-1,3(2H)-dione (WE-2) and 2-(4-((4(Bis(2-(triphenylsilyloxy)ethyl)amino)phenyl)diazenyl)benzylidene)-1H-indene-1,3(2H)-dione (WE-3). They have been synthesized in our previous research ${ }^{16}$. These materials differ only by number and type of amorphous phase creating functional groups in the molecules. Compound WE-1 contain just one trityloxyethyl group while WE-2 has two such fragments. WE-3 has two triphenylsilyl groups where two carbon atoms are substituted with silicon.

2) Isophorene fragment containing "push-pull" type molecular glasses - 2-(3-(4-(Bis(2(trityloxy)ethyl)amino)styryl)-5,5-dimethylcyclohex-2-enylidene)malononitrile $\quad$ (IWK-1D), 2-(3-(4-((4(Ethyl(2-(trityloxy)ethyl)amino)phenyl)diazenyl)styryl)-5,5-dimethylcyclohex-2-enylidene)malononitrile

(IWK-2M) and 2-(3-(4-((4-(bis(2-(trityloxy)ethyl)amino)phenyl)diazenyl)styryl)-5,5-dimethylcyclohex-2enylidene)malononitrile (IWK-2D). Compound IWK-1D been synthesized as in our previous research ${ }^{18}$. Compounds IWK-2M and IWK-2D have been synthesized similar as IWK-1D from reactants obtained previously by us ${ }^{16,18}$. Compound IWK-1D contains two trityloxyethyl fragments but does NOT contain azophenyl group. However, both other compounds - IWK-2M and IWK-2D contain the missing azobenzene fragment, but IWK-2M has one trityloxyethyl group while IWK-2D has two such fragments.

3) Pyranylidene fragment containing "push-pull" type azochromophores - 2-(2-(4-((4-(bis(2(trityloxy)ethyl)amino)phenyl)diazenyl)styryl)-6-tert-butyl-4H-pyran-4-ylidene)- $1 H$-indene-1,3(2H)-dione (ZWK-2TB), 2-(2-(4-((4-(bis(2-(trityloxy)ethyl)amino)phenyl)diazenyl)styryl)-6-tert-butyl-4H-pyran-4ylidene)malononitrile (DWK-2TB), 5-(2-(4-((4-(bis(2-(trityloxy)ethyl)amino)phenyl)diazenyl)styryl)-6-tert- 
butyl-4H-pyran-4-ylidene)pyrimidine-2,4,6(1H,3H,5H)-trione (JWK-2TB) and 2-(2-(4-((4-(bis(2(trityloxy)ethyl)amino)phenyl)diazenyl)styryl)-6-styryl-4H-pyran-4-ylidene)-1 $H$-indene-1,3(2H)-dione (ZWK3AZO). Compounds ZWK-2TB, DWK-2TB, JWK-2TB and ZWK-3AZO have been synthesized from reactants obtained previously by us ${ }^{13,16,19}$. The materials ZWK-2TB, DWK-2TB and JWK-2TB differ only by different electron acceptor groups in the molecules - malononitrile for DWK-2TB, indene-1,3-dione for ZWK2TB and barbituric acid for JWK-2TB. Both compounds - ZWK-2TB and ZWK-3AZO have indene-1,3dione as electron acceptor part in their structures. However, ZWK-2TB contain tert-butyl group, while in case of ZWK-3AZO it is substituted with styryl group.<smiles>CCN(CCOC(c1ccccc1)(c1ccccc1)c1ccccc1)c1ccc(N=Nc2ccc(C=C3C(=O)c4ccccc4C3=O)cc2)cc1</smiles><smiles>CC1(C)CC(/C=C/c2ccc(N(CCOc3ccccc3)c3ccccc3)cc2)=CC(=C(C#N)C#N)C1</smiles><smiles>O=C1C(=O)c2ccccc2C1=Cc1ccc(N=Nc2ccc(N(CCOc3ccccc3)c3ccccc3)cc2)cc1</smiles><smiles>CCN(CCOc1ccccc1)c1ccc(N=Nc2ccc(/C=C/C3=CC(=C(C#N)C#N)CC(C)(C)C3)cc2)cc1</smiles><smiles>O=C1C(=Cc2ccc(N=Nc3ccc(N(CCCO[Pb](c4ccccc4)(c4ccccc4)c4ccccc4)CCO[Sb](c4ccccc4)(c4ccccc4)c4ccccc4)cc3)cc2)C(=O)c2ccccc21</smiles><smiles>CC1(C)CC(=CC=Cc2ccc(N=Nc3ccc(N(CCOc4ccccc4)CCOc4ccccc4)cc3)cc2)C=C(C(C#N)C#N)C1</smiles>

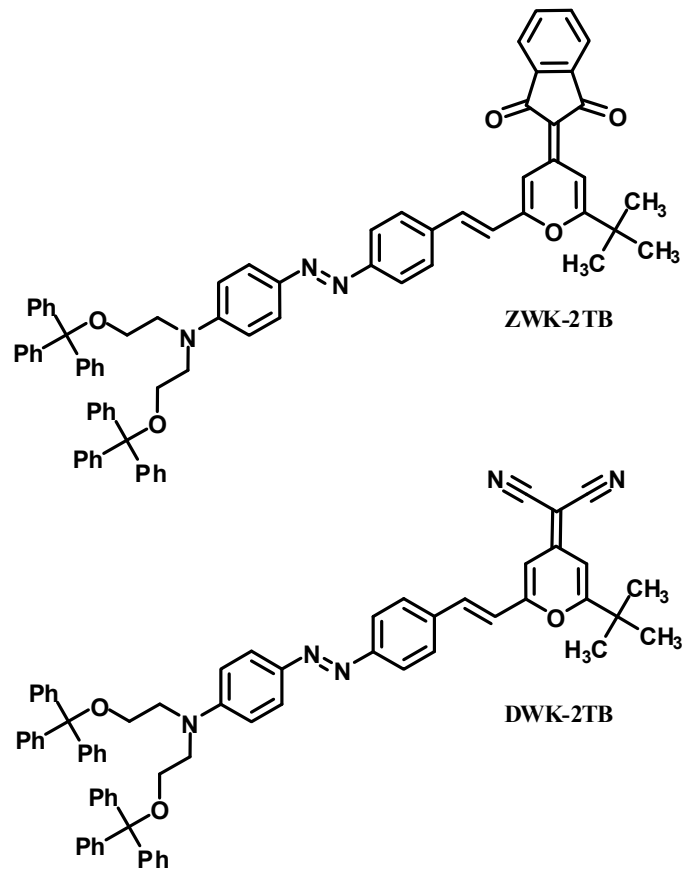<smiles>CC(C)(C)C1=CC(=C2C(=O)NC(=O)NC2=O)C=C(C=Cc2ccc(N=Nc3ccc(N(CCCN(CCOC(c4ccccc4)(c4ccccc4)c4ccccc4)c4ccccc4)CCOC(c4ccccc4)(c4ccccc4)c4ccccc4)cc3)cc2)O1</smiles><smiles>O=C1C(=C2C=C(C=Cc3ccccc3)C=C(C=Cc3ccc(N=Nc4ccc(N(CCOc5ccccc5)CCOc5ccccc5)cc4)cc3)O2)C(=O)c2ccccc21</smiles>

Figure 1. Investigated low-molecular mass and glass-forming organic compounds 


\subsection{Sample preparations for optical characterization}

For absorption measurements in the solution, the investigated compounds were dissolved in dichloromethane at $10^{-5} \mathrm{M}$ concentration. For absorption determination in the solid state, thin films were deposited on quartz glass by spin-coating technique. Before the deposition of the layers, the quartz glass substrates were cleaned in dichloromethane. The compound saturated solutions of dichloromethane were spin-coated on glass substrates for $40 \mathrm{~s}$ at $1000 \mathrm{rpm}$ and 1000 $\mathrm{rpm} / \mathrm{s}$ acceleration. For nonlinear optical property investigation, the films from their diluted solution of chloroform were spin-coated with a Laurell WS-400B-NPP/LITE spin-coater on indium tin oxide covered glass substrates. For holographic property determination, the investigated compounds were spin-coated on glass substrates for $120 \mathrm{~s}$ at 200 $\mathrm{rpm}$ and $500 \mathrm{rpm} / \mathrm{s}$ acceleration from their saturated solutions in chloroform.

\subsection{Measurement systems}

Differential scanning calorimetry (DSC) measurements were carried out by using Mettler Toledo DSC 1/200W equipment under nitrogen atmosphere and Simultaneous Thermal Analyzer STA 6000. Thermogravimetric analysis (TGA) measurements were made by using Simultaneous Thermal Analyzer STA 6000.

Absorption spectra of the compounds in dichloromethane solution were measured by Perkin Elmer Lamda 35 spectrometer. Absorption spectra of the thin films were measured by an Ocean Optics HR4000 spectrometer.

Holographic gratings with the period of $2 \mu \mathrm{m}$ were recorder by KLASTECH DENICAFC 532-300 diode pumped solid state laser $(\lambda=532 \mathrm{~nm})$. The holographic grating readout were carried out with Melles Griot 25LH928-230 He-Ne gas laser $(\lambda=632.8 \mathrm{~nm})$. Linear $\mathrm{p}$-p recording beam light polarizations were used for our experiments.

All optical measurements were carried out in ambient atmosphere at room temperature.

\section{RESULTS AND DISCUSSION}

\subsection{Thermal properties}

The thermal property measurements were carried out according to the procedures reported in our previous researches ${ }^{12-}$ 13. TGA measurement results of the compounds are shown in Fig.2. Changes in mass relative to starting mass were determined in the temperature range from $+30^{\circ} \mathrm{C}$ to $+510^{\circ} \mathrm{C}$ at a heating rate of $10^{\circ} \mathrm{C} / \mathrm{min}$. The $\mathrm{T}_{\mathrm{d}}$ values were taken at the level of $5 \%$ weight loss. The most thermally stable compound - DWK-2TB with $\mathrm{T}_{\mathrm{d}}=320^{\circ} \mathrm{C}$ contain pyranylidene fragment in its molecule along with malononitrile as electron acceptor group. Isophorene fragment containing compounds - IWK-1D, IWK-2M and IWK-2D thermal stability is similar with the other azochromophores with pyranylidene groups - ZWK-2TB, JWK-2TB and ZWK-3AZO with $\mathrm{T}_{\mathrm{d}}$ from $288^{\circ} \mathrm{C}$ to $298^{\circ} \mathrm{C}$. The least thermally stable compound was WE-1 with the $\mathrm{T}_{\mathrm{d}}=250^{\circ} \mathrm{C}$. Nevertheless, the thermal stability of azochromophores WE-2 and WE3 who have similar structure as $\mathbf{W E}-1$ are higher by $30^{\circ} \mathrm{C}$ to $32^{\circ} \mathrm{C}$. The reason of such rapid chance of thermal stability for azobenzene group containing molecular glasses with indene-1,3-dione as electron acceptor fragment (WE-1, WE-2, WE-3) is most likely the number of triphenyl groups in the molecules. At the same time the number of triphenyl groups in the molecules containing isophorene fragment (IWK-2M, IWK-2D) do not influence their thermal stability.

The DSC measurements of the investigated compounds were carried out as described in ${ }^{12,15}$ and are summarized in Fig.3. From all of the investigated compounds the JWK-2TB has the highest glass transition $\left(\mathrm{T}_{\mathrm{g}}\right)$ value $-180^{\circ} \mathrm{C}$. Comparing with pyranylidene fragment containing compounds ZWK-2TB and DWK-2TB which have similar structure - their $T_{g}$ values are $120^{\circ} \mathrm{C}$ and $115^{\circ} \mathrm{C}$. Such high difference could be explained by the hydrogen bond formation between the JWK-2TB molecules from pyrimidine-2,4,6(1H,3H,5H)-trione electron acceptor fragment. Compounds ZWK-2TB and ZWK-3AZO both have also similar structures. However for ZWK-3AZO the $\mathrm{T}_{\mathrm{g}}=176^{\circ} \mathrm{C}$ while $\mathbf{Z W K - 2 T B}$ it is $120^{\circ} \mathrm{C}$. The $\mathrm{T}_{\mathrm{g}}$ values of isophorene fragment containing compounds (IWK-1D, IWK-2M, IWK-2D) are lower than for pyranylidene and are in range from $90^{\circ} \mathrm{C}$ to $105^{\circ} \mathrm{C}$. The $\mathrm{T}_{\mathrm{g}}$ value increases by the number of triphenylmethyl groups and additional insertion of azophenyl fragment in the molecules. Glasses WE-1, WE-2 and WE-3 had lowest $T_{g}$ values (from $70^{\circ} \mathrm{C}$ to $98^{\circ} \mathrm{C}$ ). Same relation as for isophorene containing glasses was observed - the $\mathrm{T}_{\mathrm{g}}$ increases with additional incorporation of triphenylmethyl groups in the molecule. However, WE-3 containing triphenylsilil groups had lower $\mathrm{T}_{\mathrm{g}}$ values by $23^{\circ} \mathrm{C}$ comparing to $\mathbf{W E - 2}$ containing triphenylmethyl groups while both having almost identical chemical structures. 

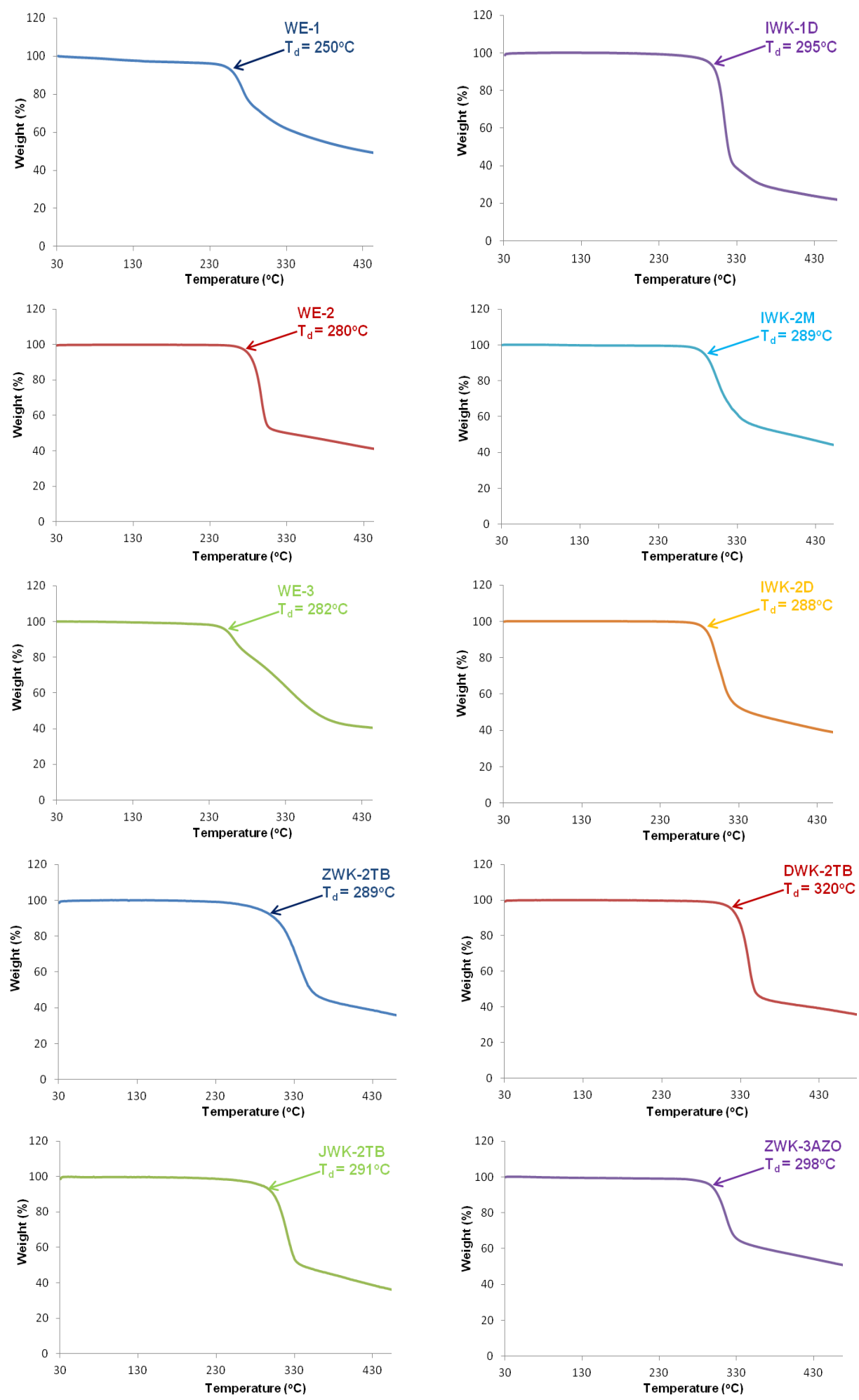

Figure 2. Thermogravimetric analysis of the investigated compounds 

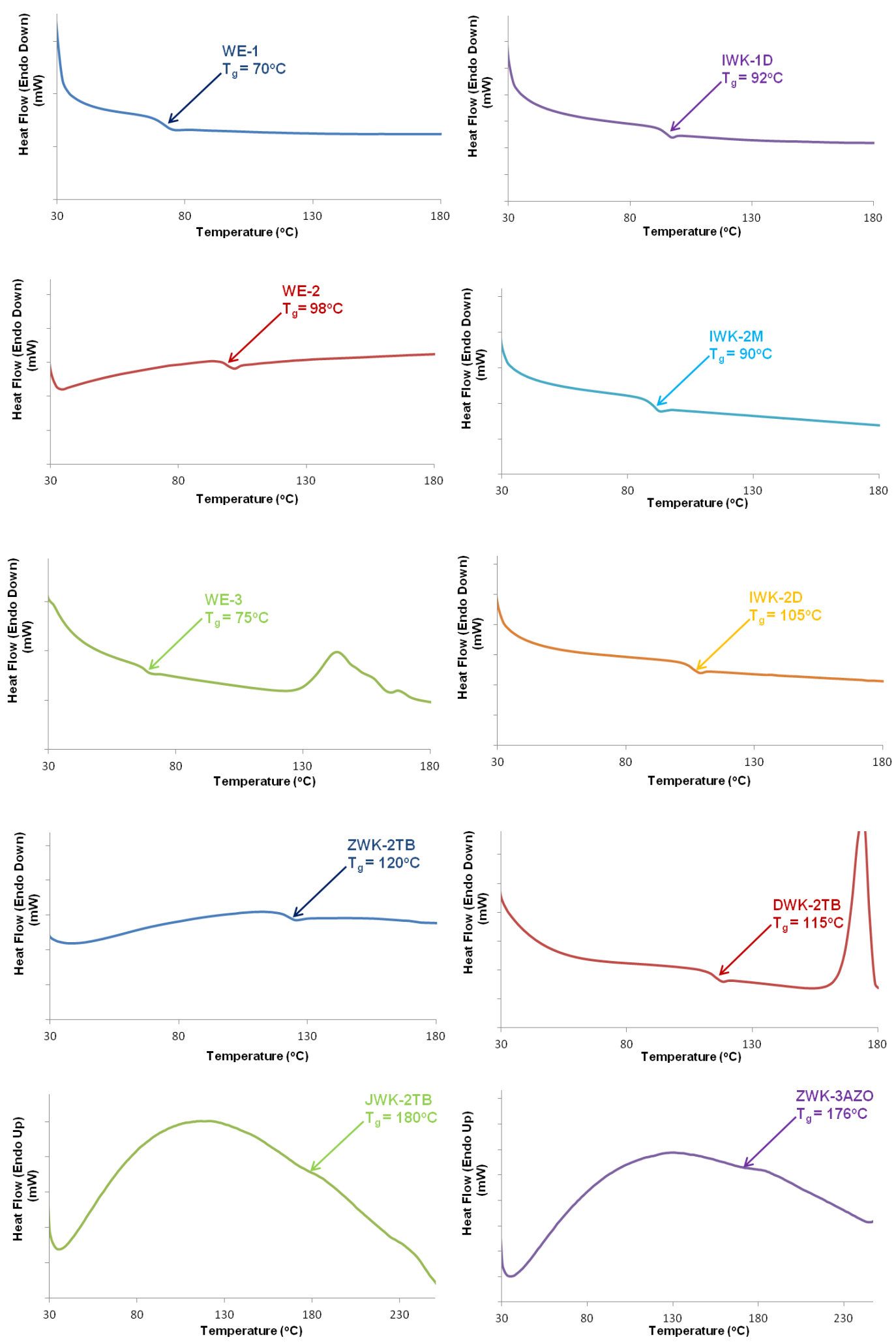

Figure 3. DSC thermogramms of the investigated compounds 


\subsection{Glass-forming properties}

The surface of the prepared spin-coated films of the investigated compounds on the glass substrate were observed by the optical microscope Nikon Eclispe 150L. The obtained images are shown in [Fig.4.].

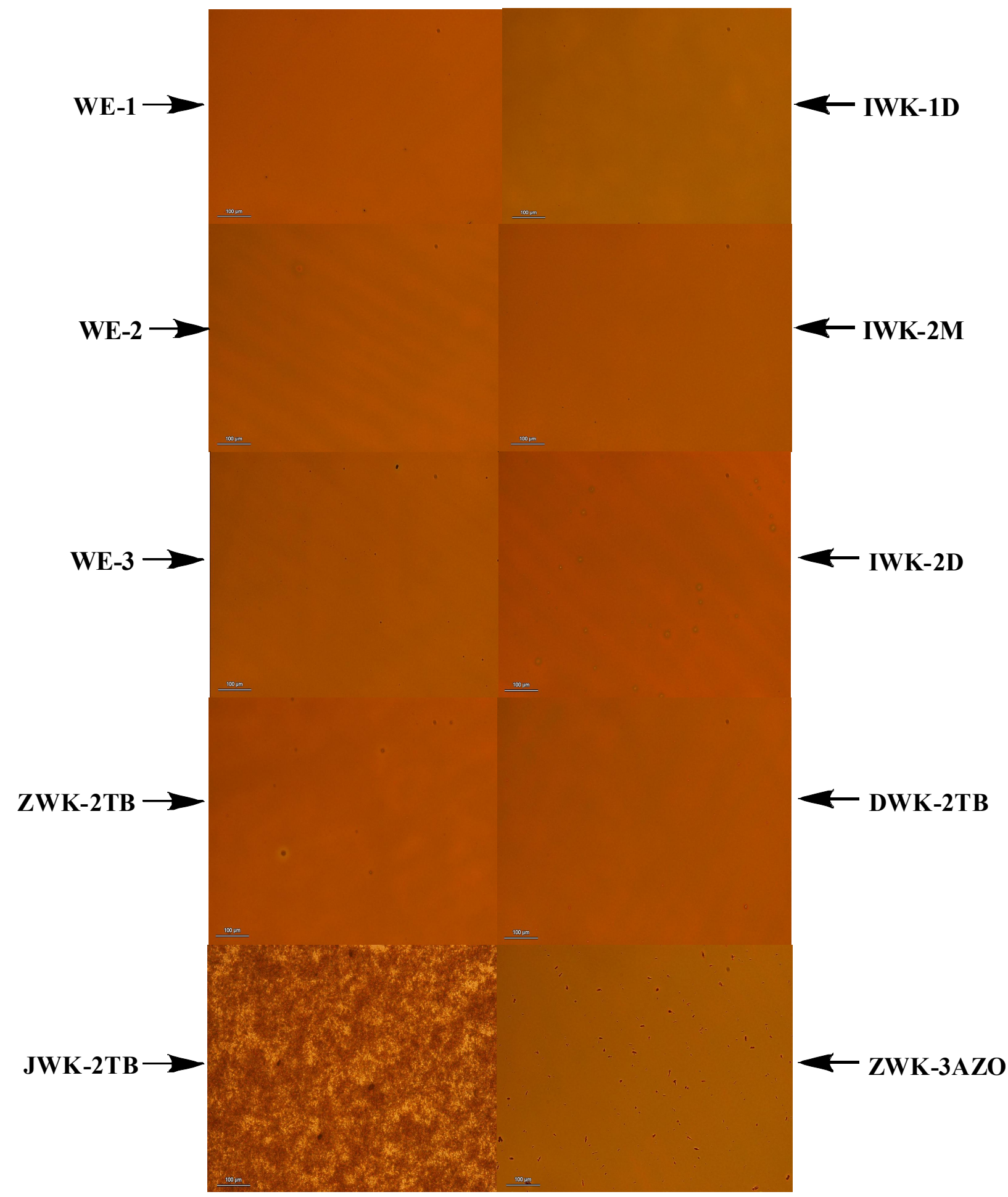

Figure 4. Optical microscope images of the pure films of the investigated compounds. Dots on the neat film surface represent compound crystalline state while the rest smooth area shows amorphous solid state. 
Glasses WE-1, WE-2, WE-3, IWK-1D, IWK-2M, IWK-2D, ZWK-2TB and DWK-2TB show very small crystalline state areas in their pure films. However, the pure film obtained from compound JWK-2TB is full of crystals which could be caused by too strong interaction of molecules caused by already mentioned hydrogen bonds in the electron acceptor part of the molecule. Film obtained from ZWK-3AZO have more crystal formations, but also has lot of amorphous area. The reason for increased crystalline state in this molecule could be explained by the possible formation of dimers. The glass-forming properties of the all investigated compounds with the exception of JWK-2TB could be still increased by adding some polymer matrix to the compound before the preparation of the neat films.

\subsection{Optical properties}

For the further measurement of nonlinear optical and holographic properties of ALL investigated compounds, it was required to measure their absorption properties in solutions of dichloromethane and thin solid films. The results of these measurements are shown in Fig.5. and Fig.6.

1)
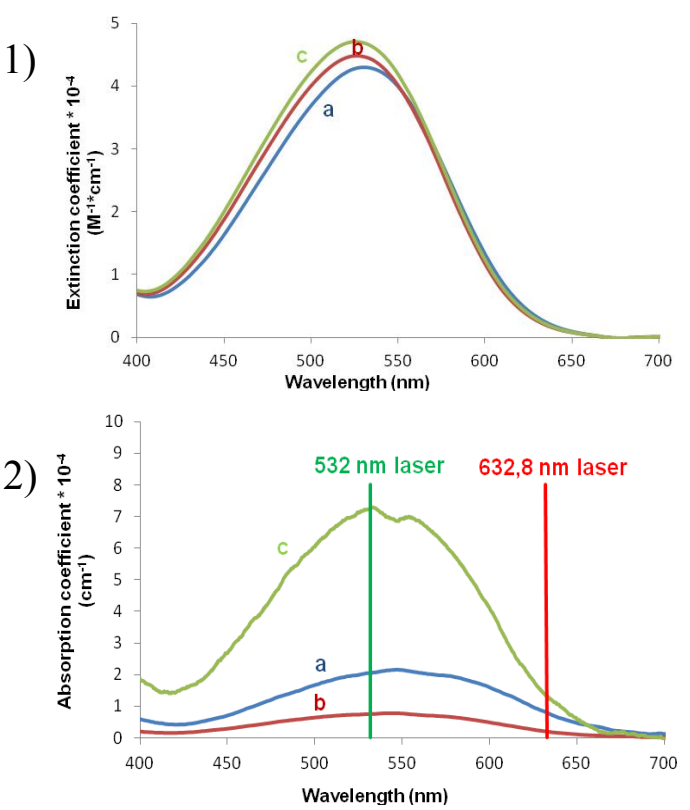
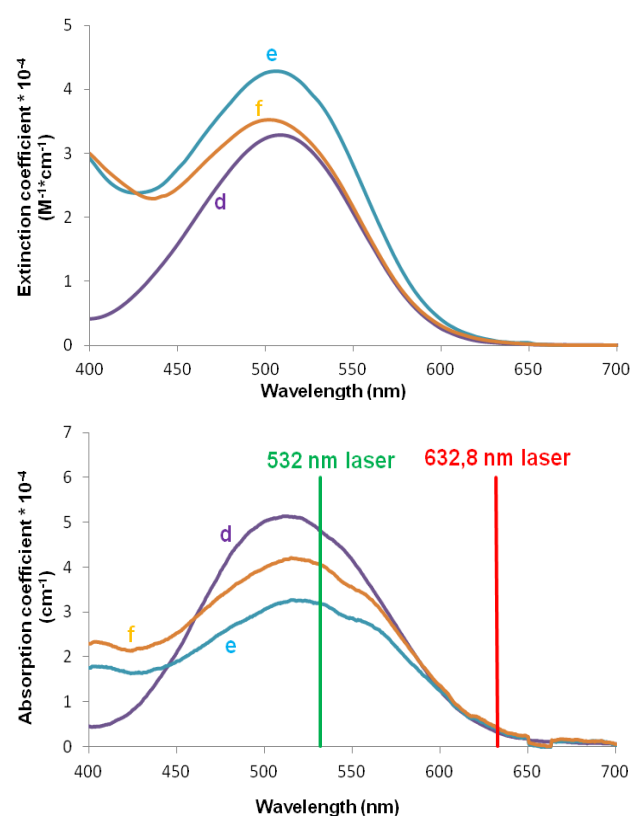

Figure 5. Absorption spectra of compounds in

1) Solution of dichloromethane and 2) Pure spin-coated films

a) WE-1, b) WE-2, c) WE-3, d) IWK-1D, e) IWK-2M, f) IWK-2D

The absorption maxima of all investigated compounds in the solid state (from $490 \mathrm{~nm}$ to $540 \mathrm{~nm}$ ) is red-shifted by 10 $20 \mathrm{~nm}$ from their solutions of dichloromethane (from $480 \mathrm{~nm}$ to $520 \mathrm{~nm}$ ). For glasses containing pyranylidene fragment in the molecule (ZWK-2TB, DWK-2TB and ZWK-3AZO) their absorption is blue-shifted by 10-20 nm comparing with molecules WE-1, WE-2, WE-3, IWK-1D, IWK-2M and IWK-2D. It could be attributed to the additional small conjugation caused by the oxygen and the double bond in the molecules of ZWK-2TB, DWK-2TB and ZWK-3AZO which causes a hipsochromic shift of the absorption. Due to the poor glass-forming properties [Fig.4.] we were unable to obtain the absolute absorption in neat film for JWK-2TB. Nevertheless, since the absorption of almost all of the investigated compounds of the pure films is close to $532 \mathrm{~nm}$, we could use the laser with such wavelength for holographic recording in our next experiments. Investigated compounds still had some absorption at $632.8 \mathrm{~nm}$ so a laser with the already mentioned wavelength could be used for the readout for the obtained surface relief gratings and holographic properties. 

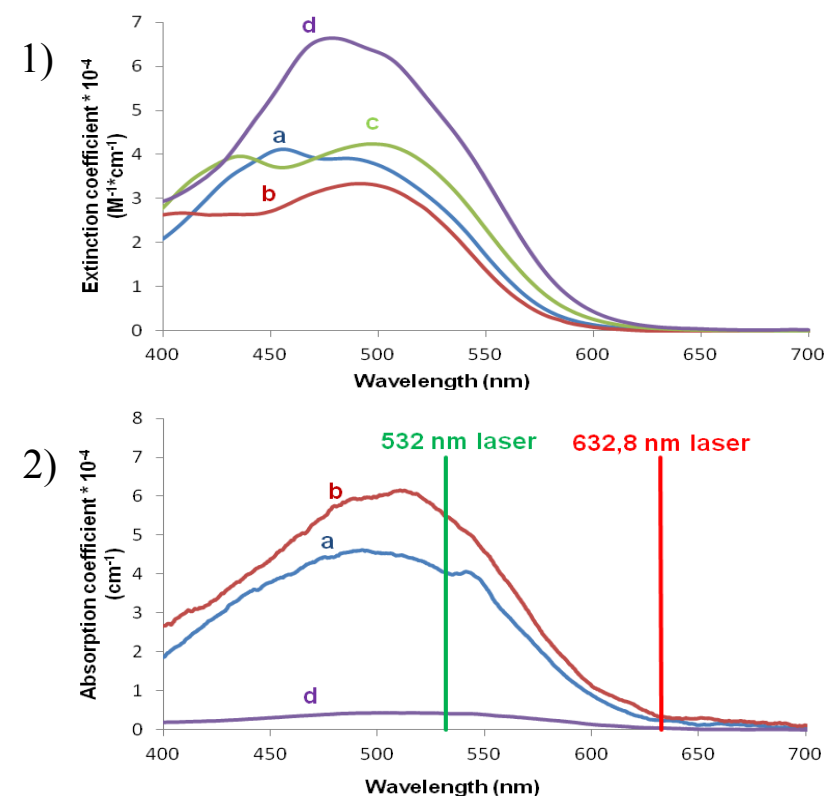

Figure 6. Absorption spectra of compounds in

1) Solution of dichloromethane and 2) Pure spin-coated films

a) ZWK-2TB, b) DWK-2TB, c) JWK-2TB, d) ZWK-3AZO

\subsection{Nonlinear optical properties}

The preparation of the samples and optical measurements were carried out as described in our previous researches ${ }^{9,11,20}$.

Despite the good glass-forming properties of the compounds WE-1, WE-2, WE-3, DWK-2TB and ZWK-3AZO on the glass-surface, their obtained pure films on ITO glass start to crystallize upon the orientation. Therefore we were unable to determine their nonlinear properties. However we have obtained excellent pure films from compounds IWK-1D, IWK-2M, IWK-2D and ZWK-2TB on ITO glass and measured their nonlinear properties which are summarized in table 1 .

Table 1. Nonlinear optical properties of thin films of compounds IWK-1D, IWK-2M, IWK-2D and ZWK-2TB.

\begin{tabular}{|c|c|c|c|c|c|c|}
\hline Structure & $\mathrm{T}_{\mathrm{SHI50}}\left({ }^{\circ} \mathrm{C}\right)$ & $\begin{array}{c}\text { Orientation } \\
\mathbf{T}\left({ }^{\circ} \mathrm{C}\right)\end{array}$ & $\begin{array}{c}d_{33}(532) \\
(p m / V)\end{array}$ & $\begin{array}{c}d_{31}(532) \\
(p m / V)\end{array}$ & $\begin{array}{c}\mathrm{d}_{14}(532) \\
(\mathrm{pm} / \mathrm{V})\end{array}$ & $\begin{array}{l}\mathrm{d} 33(0) \\
(\mathrm{pm} / \mathrm{V})\end{array}$ \\
\hline IWK-1D & 76 & 80 & 98.8 & 55.9 & 50.4 & 2.23 \\
\hline IWK-2M & 74 & 78 & 62.8 & 40.6 & 35.3 & 2.84 \\
\hline IWK-2D & 84 & 90 & 125.7 & 75.4 & 48.4 & 6.05 \\
\hline ZWK-2TB & 100 & 108 & 66.2 & 28.7 & 19.9 & 7.34 \\
\hline
\end{tabular}

The nonlinear optical coefficients $\mathrm{d}_{33}, \mathrm{~d}_{31}$ and $\mathrm{d}_{14}$ are higher for isophorene type glasses (IWK-1D, IWK-2M, IWK-2D) then compounds containing pyranylidene fragment (ZWK-2TB). However, the temperature of 50\% NLO intensity decay $\mathrm{T}_{\mathrm{SHI50}}$ value is higher for ZWK-2TB by $25^{\circ} \mathrm{C}$ to $15^{\circ} \mathrm{C}$ comparing to IWK-1D, IWK-2M and IWK-2D. From isophorene fragment containing glasses, the compound IWK-2D showed the highest NLO efficiency values and highest thermal 
characteristics. The reason for it could be the incorporation of two triphenylmethyl groups in the molecule which enhances the orientation of the molecules in their pure films before the optical measurements.

\subsection{Holographic properties}

The holographic investigation of the thin films obtained from the compounds was carried out with the equipment and according to our previous researches ${ }^{16-17}$. The thickness of each film was found by using the light transmission and absorption at $632.8 \mathrm{~nm}$. All samples were subjected to laser irradiation (power of both laser beams $=8.5 \mathrm{~mW}$ ) for certain amount of time ( $\mathbf{t}, \mathbf{m i n})$. Two photodiodes were used to detect diffracted beams (SDE and DE) and measure the self diffraction efficiency $\left(\mathbf{S D E}_{\mathbf{t}}\right)$ and diffraction efficiency $\left(\mathbf{D E}_{\mathbf{t}}\right)$. $\mathbf{D E} \mathbf{E}_{\mathbf{t}}$ was measured with $632.8 \mathrm{~nm}$ laser. All results were measured in transmission mode and are shown in table 2 and table 3.

Table 2. Holographic properties of thin films of investigated compounds at $532 \mathrm{~nm}$.

\begin{tabular}{|c|c|c|c|c|c|c|c|}
\hline Sample & $\begin{array}{c}\text { Thickness of } \\
\text { film }(\boldsymbol{\mu m})\end{array}$ & $\begin{array}{c}\text { SDE } \\
(\boldsymbol{\mu W})\end{array}$ & $\mathbf{t}, \mathbf{m i n}$ & $\begin{array}{c}\text { SDEt, } \\
(\%)\end{array}$ & $\mathbf{T}, \mathbf{( \% / s )}$ & $\mathbf{W}_{\max }$ & $\mathbf{R E F}_{\max }$ \\
\hline WE-1 & 0.5 & 104.0 & 12 & 1.23 & 0.0017 & 196.93 & 0.0062 \\
\hline WE-2 & 3.9 & 2.0 & 9 & 0.03 & $<0.0001$ & 7680.12 & $<0.0001$ \\
\hline WE-3 & 0.2 & 20.0 & 6 & 0.24 & 0.0007 & 512.01 & 0.0005 \\
\hline IWK-1D & 1.1 & 55.0 & 9 & 0.65 & 0.0012 & 279.28 & 0.0023 \\
\hline IWK-2M & 0.9 & 320.0 & 8 & 3.77 & 0.0078 & 42.67 & 0.0882 \\
\hline IWK-2D & 0.7 & 1100.0 & 24 & 12.94 & 0.0090 & 37.24 & 0.3475 \\
\hline ZWK-2TB & 0.2 & 130.0 & 10 & 1.53 & 0.0026 & 131.29 & 0.0117 \\
\hline DWK-2TB & 0.2 & 90.0 & 9 & 1.07 & 0.0020 & 170.67 & 0.0062 \\
\hline ZWK-3AZO & 4.1 & 200.0 & 9 & 2.36 & 0.0043 & 76.80 & 0.0306 \\
\hline
\end{tabular}

Table 3. Holographic properties of thin films of investigated compounds at $632.8 \mathrm{~nm}$.

\begin{tabular}{|c|c|c|c|c|c|c|c|}
\hline Sample & $\begin{array}{c}\text { Thickness of } \\
\text { film }(\boldsymbol{\mu m})\end{array}$ & $\mathbf{D E}(\boldsymbol{\mu W})$ & $\mathbf{t}, \mathbf{m i n}$ & $\begin{array}{c}\mathbf{D E t}, \\
\mathbf{( \% )}\end{array}$ & $\mathbf{T}, \mathbf{( \% / s )}$ & $\mathbf{W}_{\max }$ & $\mathbf{R E F}_{\max }$ \\
\hline WE-1 & 0.5 & 23.5 & 12 & 4.70 & 0.0065 & 4.51 & 1.4300 \\
\hline WE-2 & 3.9 & 7.0 & 12 & 1.40 & 0.0019 & 15.13 & 0.0930 \\
\hline WE-3 & 0.2 & 6.5 & 8 & 1.30 & 0.0027 & 10.86 & 0.1200 \\
\hline IWK-1D & 1.1 & 9.7 & 3 & 1.94 & 0.0108 & 2.73 & 0.7109 \\
\hline IWK-2M & 0.9 & 45.0 & 9 & 9.00 & 0.0167 & 1.77 & 5.1000 \\
\hline IWK-2D & 0.7 & 102.0 & 24 & 20.40 & 0.0142 & 2.08 & 9.8300 \\
\hline ZWK-2TB & 0.2 & 2.0 & 12 & 0.40 & 0.0006 & 52.94 & 0.0076 \\
\hline DWK-2TB & 0.2 & 5.0 & 10 & 1.00 & 0.0017 & 17.65 & 0.0567 \\
\hline ZWK-3AZO & 4.1 & 41.0 & 12 & 8.20 & 0.0112 & 2.58 & 3.1750 \\
\hline
\end{tabular}


The samples prepared from the isophorene group containing compounds showed the highest self diffraction $(13 \%$ for IWK-2D and almost 4\% for IWK-2M) and diffraction (20\% for IWK-2D and $9 \%$ for IWK-2M) efficiencies followed by the sample prepared by pyranylidene group containing compound ZWK-3AZO with $2 \%$ self diffraction efficiency and $8 \%$ diffraction efficiency and azobenzene derivate WE-1 with $1 \%$ self diffraction efficiency and $4 \%$ diffraction efficiency. The least effective holographic data storage properties were observed for other pyranylidene fragment containing compounds DWK-2TB, ZWK-2TB and other azobenzene derivatives WE-2, WE-3 with diffraction and self diffraction efficiencies about $1 \%$ and lower.

\section{CONCLUSIONS}

Almost all of the synthesized molecular glasses - WE-1, WE-2, WE-3, IWK-1D, IWK-2M, IWK-2D, ZWK-2TB, DWK-2TB and ZWK-3AZO form amorphous structure from their solutions of volatile organic solvents. All glasses show good thermal stability with thermal decomposition temperatures from $250^{\circ} \mathrm{C}$ to $320^{\circ} \mathrm{C}$. The glass transition temperatures of investigated compounds are higher than $70^{\circ} \mathrm{C}$ and even up to $180^{\circ} \mathrm{C}$ for JWK-2TB. However, JWK2TB showed very poor formation of amorphous structure and solubility in solutions of chloroform and dichloromethane. Although the glasses with isophorene fragment in their molecules (IWK-1D, IWK-2M, IWK-2D) showed just average glass transition values (from $90^{\circ} \mathrm{C}$ to $105^{\circ} \mathrm{C}$ ), from all of them a good quality pure films on ITO glass were obtained after the orientation and they also had not only the highest NLO efficiencies ( $\mathrm{d}_{33}$ up to $125.7 \mathrm{pm} / \mathrm{V}$ for IWK-2D), but also were the most effective holographic data storage materials with holographic self diffraction efficiency $13 \%$ and holographic diffraction efficiency $20 \%$, also for IWK-2D, which make them perspective as potential multifunctional optical materials. Other compounds with pyranylidene fragment in their molecules (ZWK-2TB, DWK-2TB, ZWK3AZO) were most thermally stable (thermal decomposition temperatures from $299^{\circ} \mathrm{C}$ to $320^{\circ} \mathrm{C}$.) and had highest glass transition values (from $115^{\circ} \mathrm{C}$ to $176^{\circ} \mathrm{C}$ ). However, not all of them had a good ability to form thin films from solutions and the highest NLO efficiency $\left(\mathrm{d}_{33}\right.$ up to $66.2 \mathrm{pm} / \mathrm{V}$ for ZWK-2TB and the highest holographic self diffraction efficiency of $2 \%$ and diffraction efficiency of $8 \%$ was observed for ZWK-3AZO.

The least effective compounds were azobenzene derivatives WE-1, WE-2, WE-3. They had the lowest thermal stabilities (from $250^{\circ} \mathrm{C}$ to $282^{\circ} \mathrm{C}$ ), lowest glass transition values (from $70^{\circ} \mathrm{C}$ to $98^{\circ} \mathrm{C}$ ). Although they had good glassforming properties from solution, they still were least effective holographic data storage materials (with diffraction and self diffraction efficiencies about $1 \%$ and lower) and no pure film obtained from them remained amorphous after orientation in the required experiments for NLO property determination. As we conducted from this reach, the glass transition and the thermal stability could be increased by incorporation of additional amorphous phase forming groups. However, not all of the molecules could maintain their amorphous structure in the solid state. This drawback could still be improved by adding additional glass-forming triphenyl group in the molecule or also by doping some of the synthesized molecules in a polymer matrix.

\section{ACKNOWLEDGEMENTS}

This work has been supported by the European Social Fund within the project «Support for the implementation of doctoral studies at Riga Technical University». Authors are grateful to Kaspars Traskovskis for useful discussion.

\section{REFERENCES}

[1] Ostroverkhova, O., and Moerner, W. E., "Organic Photorefractives: Mechanisms, Materials, and Applications," Chem. Rev., 104, 3267-3314 (2004).

[2] Min, J. C., Jeong, H. L., Chang, S. H., Jae, H. K., Ho, S. L., and Dong, H. C., "A tricyanopyrroline-based nonlinear optical chromophore bearing a lateral moiety: A novel steric technique for enhancing the electro-optic effect," Dyes Pigm., 79, 193-79199 (2008).

[3] Andreu, R., Franco, S., Galin, E., Garin, J., De Baroja, N. M., Momblona, C., Orduna, J., Alicante, R., and Villacampa, B., "Isophorone- and pyran-containing NLO-chromophores: a comparative study," Tetrahedron Lett., 51, 3662-3665 (2010). 
[4] Koeckelberghs, G., De Groof, L., Moreno, J. P., Asselberghs, I., Clays, K., Verbiest, T., and Samyn, C., "Synthesis and nonlinear optical properties of linear and $\Lambda$-shaped pyranone-based chromophores," Tetrahedron, 64, 3772-3781 (2008).

[5] Hua, J., Luo, J., Qin, J., Shen, Y., Zhang, Y., and Lu, Z., "New nonlinear optical chromophores exibiting good transparency and large nonlinearity: synthesis and characterization of chromophores with stilbene ring-locked triene as a combined conjugation bridge," J. Mater. Chem., 12, 863-869 (2002).

[6] Woo, H. Y., Shim, H. -K., and Lee, K. -S., "Synthesis and optical properties of polyurethanes containing a highly NLO active chromophore," Macromol. Chem. Phys., 199, 1427-1433 (1998).

[7] Carella, A., Borbone, F., Caruso, U., Centore, R., Roviello, A., Barsella, A., and Quatela, A., "NLO behavior of polymers containing Y-shaped chromophores," Macromol. Chem. Phys., 208, 1900-1907 (2007).

[8] Vembris, A., Rutkis, M., Zauls, V., and Laizane, E., "Stability of the functional NLO polymers-optically induced depoling of the DMABI molecules in sPMMA matrix," Thin Solid Films, 516, 8937-8943 (2008).

[9] Vembris, A., Rutkis, M., and Laizane, E., "Effect of Corona Poling and Thermo Cycling Sequence on NLO Properties of The Guest-Host System," Mol. Cryst. Liq. Cryst., 485, 125-132, (2008).

[10] Rutkis, M., Jurgis, A., Kampars, V., Vembris, A., Tokmakovs, A., and Kokars, V., "New Figure of Merit for Tailoring Optimal Structure of the Second Order NLO Chromophore for Guest-Host Polymers," Mol. Cryst. Liq. Cryst., 485, 155-166 (2008).

[11] Traskovskis, K., Mihailovs, I., Tokmakovs, A., Jurgis, A., Kokars, V., and Martins, R., "Triphenyl moieties as building blocks for obtaining molecular glasses with nonlinear optical activity," J. Mater. Chem., 22, 1126811276 (2012).

[12] Vembris, A., Zarins, E., Jubels, J., Kokars, V., Muzikante, I., Miasojedovas, A., and Jursenas, S., "Thermal and optical properties of red luminescent glass forming symmetric and non symmetric styryl-4H-pyran-4-ylidene fragment containing derivatives," Opt. Mater., 34, 1501-1506 (2012).

[13]Zarins, E., Siltane, K., Misina, E., Kokars, V., Lazdovica, K., Vembris, A., Kampars, V., Muzikante, I., and Rutkis, M., "Synthesis, optical and thermal properties of glassy trityl group containing luminescent derivatives of 2-tert-butyl-6-methyl-4H-pyran-4-one," Proc. SPIE, 8435, 84351Q-1-84351Q-7 (2012).

[14] Vembris, A., Muzikante, I., Karpicz, R., Sliauzys, G., Miasojedovas, A., Jursenas, S., and Gulbinas, V., "Fluorescence and amplified spontaneous emission of glass forming compounds containing styryl-4H-pyran-4ylidene fragment," J. Lumin., 132, 2421-2426 (2012).

[15] Vembris, A., Pudzs, K., and Muzikante, I., "Light emitting thin films of glassy forming organic compounds containing 2-tert-butyl-6-methyl-4H-pyran-4-ylidene," Proc. SPIE, 8435, 843527-1-843527-6 (2012).

[16]Zarins, E., Kokars, V., Ozols, A., and Augustovs, P., "Synthesis and properties of 1,3-dioxo-1H-inden-2(3H)ylidene fragment and (3-(dicyanomethylene)-5,5-dimethylcyclohex-1-enyl)vinyl fragment containing derivatives of azobenzene for holographic recording materials," Proc. SPIE, 8074, 80740E-1-80740E-6 (2011).

[17] Ozols, A., Kokars, V., Augustovs, P., Uiska, I., Traskovskis, K., Mezinskis, G., Pludons, A., and Saharov, D., "Polarization dependance of holographic recording in glassy azocompounds," Lith. J. Phys., 50(1), 17-25 (2010).

[18]Zarins, E., Kokars, V., and Utinans, M., "Synthesis and properties of red luminescent 2-(3-(4-(bis(2(trityloxy)ethyl)amino)styryl)-5,5-dimethylcyclohex-2-enylidene) malononitrile for organic light-emitting diodes," IOP Conf. Ser.: Mater. Sci. Eng., 2, 012-019 (2011).

[19]Zarins, E., Jubels, J., and Kokars. V., "Synthesis of red luminescent non symmetric styryl-4H-pyran-4-ylidene fragment containing derivatives for organic light-emitting diodes," Adv. Mater. Res., 222, 271-274 (2011).

[20] Tokmakovs, A., Rutkis, M., Traksovskis, K., Zarins, E., Laipniece, L., Kokars, V., and Kampars, V., "Nonlinear optical properties of low molecular organic glasses formed by triphenyl modified chromophores," IOP Conf. Ser.: Mater. Sci. Eng., 38, 012-034 (2012). 